\title{
Sobre la interpretación en Barthes: hacia una hermenéutica plural*
}

\author{
On Interpretation in Barthes: \\ Towards a Plural Hermeneutics
}

Sultana Wahnón

Facultad de Filosofía y Letras

Universidad de Granada

Campus de Cartuja s/n. Granada, 18071

swahnon@ugr.es

Orcid ID 0000-0002-7324-2030

Resumen: Este trabajo discute la extendida imagen de Roland Barthes como pensador ajeno y hasta antagónico a la interpretación, presentándole, por el contrario, como el autor de una de las contribuciones más importantes del siglo xx a la hermenéutica literaria. La hipótesis central es que Barthes se mantuvo siempre a distancia del cientificismo estructuralista, reservando un espacio propio a la tarea crítico-literaria y, por ende, a la interpretación. Se propone también entender Crítica y verdad como un explícito giro hermenéutico en la producción barthesiana, bajo la influencia de la hermenéutica del símbolo de Paul Ricoeur. Se destaca, por último, la rectificación que Barthes imprimió a su propio concepto de crítica literaria en $S / Z$, libro donde se contendría la más completa y decisiva aportación del autor a la teoría de la interpretación literaria. Al mostrar la necesidad interna de esta evolución barthesiana, el trabajo se propone, además, arrojar luz sobre lo que, todavía a día de hoy, debería ser una hermenéutica específicamente adaptada, no solo al plural del texto contemporáneo, sino también a la pluralidad o multiplicidad de escrituras o poéticas literarias.

Palabras clave: Barthes. Anti-positivismo. Giro hermenéutico. La interpretación plural. La hermenéutica del texto legible.
RECIBIDO: 9 DE MARZO DE 2018 ACEPTADO: 23 DE MARZO DE 2018

\begin{abstract}
This paper takes a stand against the commonplace understanding of Roland Barthes as indifferent or even hostile to interpretation; on the contrary, he is to be credited with having made one of the most relevant contributions to literary hermeneutics in the 2oth century. The main hypothesis is that Barthes kept himself at a distance from structuralist scientificism, in order to leave room for the task of literary criticism and consequently for interpretation. Besides, I suggest understanding Criticism and Truth as an explicit hermeneutical turn in Barthes's work, under the influence of Paul Ricoeur's hermeneutics of the symbol. Lastly, Barthes's rectification of his concept of literary criticism in $S / Z$ comes to the foreground. $S / Z$ contains the most developed and decisive contribution by Barthes to the theory of literary interpretation. By showing the internal necessity of such an evolution in Barthes's work, the paper aims at shedding light on the desideratum -still pending- of a hermeneutics specifically adapted not only to the plural of the contemporary text but also to the plurality or rather multiplicity of literary écritures and poetics.
\end{abstract}

Keywords: Barthes. Anti-Positivism. Hermeneutical Turn. Plural Interpretation. Hermeneutics of Readerly Texts.

\footnotetext{
* Este trabajo se ha realizado en el marco del proyecto de investigación "Actualidad de la hermenéutica" (FFI2013-41662-P), financiado por el Ministerio de Economía y Competitividad para el periodo 2014-2018.
} 


\section{INTRODUCCIÓN}

E n el libro que dedicó por completo a la obra y el pensamiento de Roland Barthes, Jonathan Culler se refirió a $S / Z$ como el "análisis estructural más ambicioso y extenso de Barthes”, para unas líneas más abajo establecer una radical oposición entre este tipo de análisis y la tarea interpretativa, entendida como algo completamente ajeno a las intenciones del teórico francés: "Barthes -afirmó en este sentido- no pretende interpretar Sarrasine, sino analizarlo como una construcción intertextual, producto de varios discursos culturales" (Culler 1987, 97-98). Esta lectura antihermenéutica del S/Z es extrañamente opuesta a la de otros estudiosos que, como José-Guilherme Merquior, han caracterizado $S / Z$, en cambio, en términos de "interpretación estructuralista", llegando incluso a detectar en este libro "una empecinada actitud sobreinterpretativa" (Merquior 213).

Que se pueda decir una cosa y la contraria acerca del papel de la interpretación en $S / Z$ tiene mucho que ver con la ambivalencia con que el propio Barthes trató este asunto, tanto en este libro, como en el resto de los ensayos que dedicó a cuestiones de hermenéutica literaria. En trabajos anteriores he hablado de una "resistencia a la interpretación" generalizada en todo el estructuralismo y que por consiguiente habría aquejado no solo a Barthes, sino también a Jakobson y Susan Sontag, entre otros (ver Wahnón 2012, 97). En el presente trabajo me propongo analizar de manera más detenida el caso particular de Roland Barthes dando cuenta de la especial complejidad de sus relaciones con la interpretación y la hermenéutica, tal y como se formularon a lo largo de una década y desde que en 1960 publicara el primero de los ensayos contenidos en Sur Racine (1963a). El objetivo del trabajo es doble: en primer lugar, destacar el carácter netamente hermenéutico de muchas de las reflexiones llevadas a cabo por el autor durante esa década; en segundo lugar, indagar en las transformaciones que a lo largo de dicho periodo fue experimentando su discurso sobre la interpretación, poniendo así de relieve el giro hermenéutico que se inició en Crítica y verdad (1966) y que culminó de manera sorprendente en $S / Z(1970)$.

\section{UN ESTRUCTURALISMO SUI GENERIS}

Lo primero que conviene advertir aquí es que las reservas de Barthes hacia la interpretación, primero, y hacia la hermenéutica después no estuvieron motivadas nunca por una concepción cientificista de la tarea crítico-literaria. Su 
caso habría sido, pues, muy diferente al del antiguo formalista Roman Jakobson, quien, como se recordará, dedicó las primeras páginas de "Lingüística y poética" (1958) a establecer una clara línea divisoria entre el "análisis científico objetivo del arte verbal" y el discurso que por entonces llevaba el nombre de "crítica literaria". En la argumentación jakobsoniana este segundo discurso, asociado a lo "subjetivo" y a los "gustos y opiniones particulares de un crítico", quedaba por principio excluido de una concepción renovada, científica, de los "estudios literarios" o "poética" (Jakobson 350). Aunque sus análisis acabaran siendo más subjetivos e interpretativos de lo que él mismo pretendió (ver Wahnón 2012, 99-100), estas tesis son justamente las que autorizan a ver en Jakobson a un genuino representante del estructuralismo cientificista.

Las posiciones de Roland Barthes habrían sido, en cambio, bastante distintas, incluso en el periodo de su producción que se tiene por rigurosamente estructuralista. Aunque es completamente cierto que su pensamiento crítico atravesó una etapa de "ciencia" o de "cientificidad" (ver Chico Rico 31), su concreta cientificidad no habría sido del todo idéntica a la de Jakobson. Por supuesto, en los trabajos barthesianos de este periodo también se distinguía entre poética (o ciencia de la literatura) y crítica literaria, pero sin que esta diferenciación implicase el destierro de la segunda del ámbito de los estudios literarios (ver Albaladejo). Lo que defendió, tanto en los Ensayos críticos (1964), como sobre todo en Crítica y verdad (1966), fue más bien la necesaria coexistencia o cohabitación de las dos actividades, a cada una de las cuales asignó una parte igualmente importante del trabajo sobre la literatura: la interrogación sobre "las condiciones del contenido, es decir, de las formas", en el caso de la ciencia (Barthes 1966, 59); la "producción” de sentidos, en el de la crítica (66). Es más, de haber tenido que inclinarse por uno de los dos discursos, es muy probable que Barthes lo hubiera hecho a favor de la crítica, única actividad a la que de hecho concedió el privilegio ontológico de la existencia, en contraposición con la todavía inexistente ciencia: "Poseemos - dijo al respecto de la ciencia- una historia de la literatura, pero no una ciencia de la literatura" (58). A diferencia de Jakobson, para quien la ciencia literaria no solo era una realidad, sino la única realidad deseable, Barthes la entendió más bien como un futurible, algo que podía advenir, y que, caso de hacerlo -"si algún día existe", escribió-, lo haría de manera necesariamente limitada: no como una ciencia en sentido estricto, sino solo como "cierta ciencia de la literatura" (58).

Todas estas reservas y cautelas se desvanecían, en cambio, cuando el objeto de reflexión de Crítica y verdad era ese otro discurso necesariamente sub- 
jetivo y rotundamente no científico que, a juicio de Barthes, era la crítica literaria. El apartado "La crítica" comenzaba, en efecto, con un explícito reconocimiento de su carácter no científico: "La crítica no es la ciencia" (66). Pero este hecho, el de que la crítica no fuera un discurso científico -ni tan siquiera en "cierta" medida, como se acababa de decir de la presunta ciencia de la literatura-, no implicaba en su caso un menosprecio de esta. Muy al contrario, abundan los indicios de que Barthes se autoconcibió siempre mucho más como crítico que como científico de la literatura; y esto incluso durante el periodo estructuralista de su producción, es decir, al mismo tiempo que colaboraba con genuino interés en la empresa científica del Estructuralismo tout court. Uno de estos indicios es que, incluso en este periodo, el más "científico", no dejó de escribir crítica ("L’homme racinien", varios de sus Ensayos críticos...). Y otro, que siempre lo hizo reflexionando sobre lo que estaba haciendo (ver Albaladejo), actitud metateórica esta que, como se verá a continuación, le acabó convirtiendo en un genuino teórico de la interpretación literaria.

\section{LA CRÍTICA COMO INTERPRETACIÓN}

Con el objetivo de describir las primeras tesis de Barthes sobre el papel de la interpretación en la crítica literaria, se atenderá aquí a un trabajo del periodo estructuralista, "Histoire ou littérature?" (1960a). La raigambre hermenéutica de la reflexión aquí contenida puede inferirse fácilmente de los tres temas o motivos centrales del ensayo: el rechazo del positivismo de la Historia literaria, la caracterización de la crítica como tarea interpretativa y la afirmación de que la "objetividad", en el sentido científico-positivista del término, no era algo que pudiera ni esperarse ni exigirse de la crítica literaria.

$\mathrm{Al}$ igual que en otros trabajos de este periodo, el antagonista de "Histoire ou littérature?" era "la historia de la literatura" (Barthes 1960a, 138), ${ }^{1}$ encarnada aquí en una serie de historiadores concretos, entre los que el autor citó a Antonie Adam, Jean Orcibal, René Jasinski y, por supuesto, a Raymond Picard (156 n. 1). Y el motivo del antagonismo no era otro precisamente que la pretensión de objetividad y cientificidad de dichos historiadores, a los que el teórico aglutinó ya aquí bajo las etiquetas de crítica "universitaria" (148) y "positivista” (154). Desde la perspectiva barthesiana, idéntica a la que Gadamer estaba defendiendo por esas mismas fechas, la objetividad crítico-literaria era una

1. Este trabajo se cita aquí por la edición francesa original. Las traducciones son mías. 
"ilusoria" pretensión (156), que se derivaba directamente de una ideología, la del positivismo, heredada del siglo XIX. A la hora de afirmar el "carácter ideológico del positivismo", Barthes no pudo lógicamente apoyarse en las tesis de Gadamer (cuyo Verdad y método, de 1960, se estaba publicando el mismo año que su ensayo), pero sí lo hizo en las de Karl Mannheim, no casualmente uno de los autores de referencia del otro gran filósofo contemporáneo del comprender, el francés Paul Ricoeur. ${ }^{2}$ En lo que a Barthes respecta, la deuda con Mannheim fue reconocida en una nota a pie de página donde citó precisamente su Ideología y Utopía (1936) como el libro que había mostrado "el carácter ideológico del positivismo" (Barthes 1960a, 152 n. 1).

Fue, pues, a la luz de las tesis de Mannheim como Barthes pudo llevar a cabo su propia y personal crítica del positivismo literario, en un sentido muy similar a como lo estaban haciendo sus coetáneos Gadamer, Ricoeur y Peter Szondi. "Histoire ou littérature?" adelantaba ya por eso algunas de las tesis más conocidas de Crítica y verdad, entre ellas la del carácter necesariamente no científico de la crítica literaria, del que a juicio del autor no podía salvarla ninguna de las precauciones adoptadas por la crítica universitaria: ni el "rigor científico", ni el "aparato cientificista" (Barthes 1960a, 152). La "subjetividad" y no la objetividad era, por consiguiente, lo específico de este otro discurso, el crítico, al que por lo mismo caracterizó como gobernado por "otra lógica", "otras exigencias" y "otra responsabilidad" que las de la Ciencia o que incluso las de la Historia. ${ }^{3}$ Aunque el autor no pudo o no quiso darle a esa otra lógica el nombre de hermenéutica, el pasaje en el que se refirió a su existencia prueba que se estaba refiriendo en concreto a la lógica de la interpretación: "Es otra lógica, son otras exigencias, otra responsabilidad: se trata -explicitó- de interpretar la relación entre una obra y un individuo" (147; cursiva mía).

La aspiración a la objetividad crítico-literaria, propia de esos historiadores tradicionales, fue pues contestada en este ensayo con la tesis de que la crítica consistía siempre y necesariamente en un trabajo de interpretación y de que, por consiguiente, no se regía por "los mismos criterios de objetividad"

2. Como se sabe, Ricoeur se inspiró en Mannheim incluso para titular uno de sus más importantes trabajos, el libro Ideología y utopía (1986).

3. No es el momento aquí de profundizar en la conocida tesis de Barthes en relación con la necesidad de una nueva Historia de la literatura entendida como historia de la Institución literaria, pero sí creo conveniente destacar en el contexto de este trabajo que, para el Barthes de 1960, el saber histórico se diferenciaba del crítico-literario porque él sí podía y debía aspirar a la "objetividad" (147). 
de otras disciplinas (139). Pero, al igual que en otros ensayos del periodo, el oponente de este primer discurso barthesiano sobre la interpretación no era solo la crítica positivista, sino también una modalidad más actual de crítica literaria que el autor encarnó aquí en Lucien Goldmann y a la que dio el primer nombre de "crítica de significación" (147). Y fue sobre todo en diálogo (polémico) con esta otra crítica, la moderna, como Barthes formuló una de las que, con el tiempo, llegaron a ser sus tesis más conocidas y constantes: la de que, debido precisamente a su carácter interpretativo, la lógica del discurso crítico excluía de entrada y por principio cualquier posibilidad de dar con $e l$ significado del texto literario (149). Con esta fórmula, que tomó directamente de Goldmann, aludía aquí a lo que luego llamaría "la verdad de la obra" (ver Barthes 1966, 62). "Histoire ou littérature?" refutaba ya, pues, la por entonces extendida idea de que la obra encerraba un significado objetivo, verdadero o último, que la crítica debía "descifrar" por medio de la interpretación. En la particular teoría barthesiana de la interpretación literaria, Verdad e Interpretación fueron, pues, desde el primer momento, términos que se excluían mutuamente.

En el ensayo de 1960 las razones por las que ninguna crítica, ni tradicional ni moderna, podía dar con la verdad del texto eran de dos tipos: textuales y extratextuales. Las primeras eran de carácter semiótico-estructuralista: era la complejidad misma del "sistema significante" de la obra literaria la que convertía en ilusoria toda pretensión de abarcarla en su "total" significación (Barthes 1960a, 149). Las segundas eran, en cambio, de carácter epistemológico-hermenéutico: lo imposible de la objetividad se derivaba también de la intervención de la subjetividad lectora que, dada esa complejidad significante de la obra, se veía obligada a imponer a la significación un "corte" (coup d'arrêt), siempre desde el prisma de un "sistema de significaciones" previamente elegido y necesariamente arbitrario, como podía serlo por ejemplo el psicoanálisis (150-51). Con este último razonamiento Barthes aludía ya a lo que en "Las dos críticas" iba a describir como "crítica ideológica", es decir, a la clase de crítica que se acercaba a las significaciones de la obra literaria desde un previo sistema de ideas vinculado a una de las grandes filosofías o ideologías del momento (Barthes 1963b, 293). De ahí que, en el ensayo de 1960, Goldmann y Mauron, en tanto que representantes de dos de esas grandes filosofías, la marxista y la psicoanalítica, fueran los elegidos para ilustrar el aserto de Barthes sobre la imposibilidad de acceder al significado (verdadero, objetivo, último, total...) de la obra (1960a, 149-51). 
Tal como él lo veía, estas dos escuelas de crítica literaria estaban consiguiendo justo lo contrario de lo que pretendían. En lugar de convencer acerca de la presunta significación objetiva de la obra, lo que sus aportaciones ponían de manifiesto era que esa significación cambiaba mucho dependiendo de si se la interrogaba desde la perspectiva de su "significado histórico" (Goldmann) o de su "significado psíquico" (Mauron) (147). Más aún, ni siquiera dentro de un mismo paradigma, por ejemplo el psicológico, se podía garantizar la unidad y coherencia de los resultados, puesto que el significado descubierto variaba también mucho en función de la concreta "psicología" elegida por el crítico: la obra no podía decir lo mismo a quien la interrogaba desde una psicología decimonónica, que a quien le hacía preguntas desde el psicoanálisis (149). Por objetiva que se quisiera, la crítica de significación no podía ser "sino sistemática", limitada en sus resultados por el coup d'arrêt impuesto a "la significación" (151). Y esto desembocó en la que llegó a ser otra de las tesis más conocidas de la teoría barthesiana de la interpretación literaria: la de que la primera y única "regla objetiva" de la crítica (156) consistía precisamente en reconocer su carácter no neutral o no objetivo, anunciando su sistema de lectura y renunciando de entrada a la idea de "descifrar" la obra (148), de "decir verdad" sobre ella (156), o de "descubrir" su significado, entendido como único, verdadero y total (147).

Ahora bien, a comienzos de los años sesenta, que fue cuando Barthes empezó a elaborar esta teoría de la interpretación literaria, lo que se entendía por interpretar (y más aún por hermenéutica) era justamente esto: descifrar, dar con la verdad, con el sentido oculto, o verdadero, o único, del texto (ver Baena 12-13). De ahí que a pesar de la contundencia con que este ensayo había decretado la naturaleza necesariamente interpretativa de la tarea críticoliteraria, en los trabajos de este periodo, muchos de ellos contenidos en Ensayos críticos, optara -en una decisión que luego tuvo que rectificar- por reservar el término de "interpretación" para la clase de crítica que se caracterizaba por esa concreta manera de entender la tarea interpretativa, eludiendo en cambio su uso cuando de lo que se trataba era, en cambio, de caracterizar la clase de crítica que, como la suya propia, perseguía otro modo de practicarla. Se abrió así el periodo de la producción barthesiana caracterizado por el fenómeno al que doy el nombre de resistencia a la interpretación y que no casualmente coincidió en el tiempo con el de su participación en la empresa científica del Estructuralismo, ella misma muy reticente a aceptar el papel que la interpretación desempeñaba en sus análisis del arte verbal. 


\section{INTERPRETACIÓN/CRÍTICA ESTRUCTURAL}

Pese a todo, no puede decirse que Barthes se desdijera nunca de sus primeras tesis sobre el carácter interpretativo de la crítica. En ninguno de los ensayos escritos en esta etapa habló de la posibilidad de una crítica no interpretativa; ni tampoco le atribuyó nunca, en contradicción consigo mismo, una nueva y sorprendente capacidad de ser "objetiva". Como ya se ha avanzado, su decisión consistió solo en reservar el término "interpretación" para referirse sobre todo a ese tipo concreto de crítica que en el ensayo de 1960 había recibido el nombre de crítica de significación. Desde esta nueva perspectiva, en la que se basan precisamente las lecturas antihermenéuticas de la primera teoría barthesiana, interpretar pasó a designar preferentemente aquello que a juicio de Barthes no debía hacerse, a saber, aspirar a dar con la verdad del texto, o con su significado objetivo, oculto, secreto, etc. Se trataba de algo muy similar, aunque no idéntico, a lo defendido en el famoso "Contra la interpretación" de Susan Sontag (1964), quien también polemizó en aquellos años -posiblemente siguiendo a Barthes- contra la concreta manera en que las escuelas marxista y psicoanalítica entendían la interpretación, aunque en su caso haciendo especial hincapié en su tendencia, alegorista, a "descifrar" no tanto un sentido verdadero, cuanto un sentido oculto (Sontag 15).

El ensayo de Barthes que mejor representa este segundo momento de su teoría de la interpretación es "Las dos críticas" (1963b). El título de este trabajo hacía referencia a las dos mismas clases de crítica que había analizado ya en "Histoire ou littérature?". El teórico habló por eso, por un lado, de la "crítica que, para simplificar, llamaremos universitaria y que practica en lo esencial un método positivista heredado de Lanson"; y por otro, de aquella cuyo acercamiento a la obra se realizaba a partir de alguna de "las grandes ideologías del momento, existencialismo, marxismo, psicoanálisis, fenomenología" (Barthes 1963b, 293). Las diferencias en relación con el ensayo anterior eran dos: en primer lugar, el ámbito de la segunda crítica se extendía ahora más allá de marxismo y psicoanálisis para abarcar a un mayor número de sistemas (ideologías); en segundo lugar, su nombre no era ya el de crítica de significación, sino el de "crítica de interpretación" o "crítica ideológica" (293). De resultas de esta decisión, y como he avanzado, en los Ensayos críticos el término interpretación dejó de aludir a la índole o naturaleza misma de la crítica literaria, para referirse ya solo a una manera concreta de cultivar o entender la tarea crítico-literaria: la que trataba de acceder al verdadero significado del texto a partir de una filosofía, ideología o visión del mundo ele- 
gida por el crítico previamente a entrar en contacto con el texto así interpretado o "descifrado".

"Las dos críticas" presentaba todavía una novedad más en relación con "Histoire ou littérature?". En lugar de ser, como este, solo un trabajo de crítica de la crítica, el ensayo de 1963 contenía ya una aportación metacrítica o metateórica, o dicho de otro modo, una propuesta personal del propio Barthes sobre aquello en que debía consistir la crítica literaria. Esta tercera crítica, no recogida en el título y de la que solo habló al final del ensayo, no era otra que el "análisis inmanente" o "crítica estructural". ${ }^{4}$ Dado que la calificó de estructural y puesto que, además, la presentó en relación de diferencia con la "crítica de interpretación", se entiende que su propuesta pudiera confundirse con la de un análisis científico con vocación de objetividad y pretendidamente ajeno a toda interpretación y valoración, al estilo jakobsoniano. Nada, sin embargo, más lejos de la verdad en el caso de Barthes, quien, como ya he comentado en otro lugar, habló de análisis inmanente donde podría haberlo hecho asimismo de "interpretación inmanente" (ver Wahnón 2008, 120-24). Lo que Barthes propuso aquí no fue, por tanto, una crítica rotundamente no interpretativa o no ideológica -lo que habría sido una contradicción en los términos-, sino una crítica en la que, según explicó, "esta interpretación y esta ideología puedan decidir trabajar en un dominio puramente interior de la obra" (Barthes 1963b, 298; cursiva mía).

Así pues, Barthes no se desdijo nunca de su anterior tesis acerca del carácter necesariamente interpretativo de la crítica literaria. Antes de que sus adversarios le acusaran de ser "un maniático del desciframiento" (ver Barthes 1966 n. 6), el propio autor había reconocido el hecho -inaceptable en cambio desde una perspectiva rigurosamente estructuralista como la de Jakobson- de que ni siquiera la crítica estructural podía dejar de ser interpretativa. Debe entenderse, pues, que la teoría barthesiana de la crítica literaria fue siempre, incluso durante el periodo estructuralista, una teoría de la interpretación literaria. El peculiar estructuralismo de Barthes no se caracterizó por una renuncia a la interpretación ni, por tanto, a la búsqueda de significaciones. Su propuesta consistió, más bien, en seguir llevando a cabo esa búsqueda, solo que de manera diferente a como lo venía haciendo la que decidió llamar crítica de inter-

4. La identidad entre estas dos fórmulas no debe entenderse como sinonimia completa, puesto que, junto a la crítica estructural, Barthes habló de otras dos modalidades posibles de análisis inmanente, la "crítica fenomenológica" y la "crítica temática" (298). 
pretación. Y análisis inmanente y crítica estructural fueron, por consiguiente, los nombres que optó por darle a esa nueva modalidad de la interpretación literaria que él mismo describió así al final de "Las dos críticas": "Un trabajo que se instale en la obra, y no plantee su relación con el mundo hasta después de haberla descrito por completo desde el interior, en sus funciones, o como se dice hoy en día, en su estructura" (Barthes 1963b, 298).

Este pasaje permite sostener que, a diferencia del estructuralismo más cientificista, el de Barthes no negó nunca que la obra literaria mantuviese una "relación con el mundo", limitándose más bien a proponer que esa relación se describiese solo después de haber llevado a cabo el análisis inmanente o estructural. Se trataba, posiblemente, de usar el análisis como medio de control de las interpretaciones o, mejor dicho, de sus excesos. Para el Barthes del periodo estructuralista, la descripción de la obra "por completo desde el interior" debía contribuir a una decisión más fundamentada y lo menos ideológica posible acerca de qué sistema o lenguaje podía ser el más adecuado para hablar de sus posibles sentidos. Eso era de hecho lo que él mismo había tratado de llevar a cabo en su hasta entonces más importante trabajo de crítica literaria, "L'homme racinien" (1960b). Tal como el propio Barthes explicó en el prólogo de Sur Racine, este trabajo constaba de dos partes u operaciones igualmente importantes: la analítico-estructural, por la que las tragedias de Racine eran tratadas "como un sistema de unidades (las 'figuras') y de funciones"; y la psicoanalítica, por la que se exploraban las posibles significaciones de esas tragedias a partir de uno de los muchos "lenguajes" (sistemas, filosofías, ideologías, etc.) de que se disponía en el rico panorama intelectual del momento, si bien con la salvedad de que en su trabajo ese lenguaje había sido elegido solo después de realizado el análisis y de haber llegado a la conclusión de que las tragedias racineanas ponían en escena a "un hombre encerrado" (1963a, 6). Aunque en este concreto momento, el de la resistencia a la interpretación, no caracterizó esta segunda operación como interpretativa, parece evidente que el teórico no entendió por crítica estructural lo mismo que Jakobson había entendido por análisis científico objetivo.

A la hora de entender esta propuesta barthesiana como genuinamente hermenéutica, resulta de utilidad también compararla con la hermenéutica del texto que Paul Ricoeur propuso una década después y que consistía en una muy parecida articulación entre una primera fase analítico-estructural y una segunda fase de atención al "sentido" de los textos, articulación en la que el filósofo francés hizo residir precisamente "la dinámica de la lectura interpreta- 
tiva" (Ricoeur 1995, 86). Para el Ricoeur de Teoría de la interpretación, era también el advenimiento de la ciencia estructuralista del lenguaje lo que obligaba a una hermenéutica literaria actual a redescribir su tarea en términos de "dialéctica de la explicación y la comprensión”, donde la explicación, la parte "científica" del trabajo, adoptaba la forma de un análisis estructural del texto; y la comprensión, la parte hermenéutica, consistía en realizar conjeturas sobre el/los posible/s sentido/s del mismo (87).

Se trataba, pues, de algo muy similar a lo defendido anteriormente por Barthes, aunque eso no significa que estemos ante dos propuestas completamente idénticas, no solo porque Barthes no usó el término tabú, sino sobre todo porque Ricoeur hizo un mayor énfasis en el carácter dialéctico de la relación entre las dos operaciones críticas, que por su parte no describió en términos de anterioridad-posterioridad, sino de simultaneidad o circularidad hermenéutica: puesto que el análisis no podía comenzar sin una previa conjetura, y puesto que a su vez las conjeturas debían ir rectificándose mediante el análisis, el filósofo concluyó que explicación y comprensión no podían entenderse como fases separadas e independientes del trabajo interpretativo, sino en estrecha y continua interrelación una con otra. De manera consecuente con esta tesis, la hermenéutica estructural de Ricoeur no hizo suya la tesis de la necesaria suspensión de la "dimensión 'mundana' del discurso" en la fase explicativa del método, polemizando abiertamente en este aspecto (y solo en este) con la "forma de leer" ejemplificada por "las distintas escuelas estructurales de la crítica literaria" (93).

\section{EL GIRO HERMENÉUTICO}

Si se tienen en cuenta estas afinidades, no puede sorprender que el propio Barthes empezara a partir de cierto momento a reparar él mismo en la relación que su peculiar estructuralismo mantenía con la hermenéutica. El acontecimiento se hizo visible en el libro más importante del periodo, Crítica y verdad (1966). Aunque su objeto seguía siendo la crítica, no la interpretación, Barthes dejó aquí de reprimir de manera sistemática el uso del término tabú. Retomando el espíritu del ensayo "Histoire ou littérature?", Crítica y verdad dio otra vez cabida al viejo argumento de que la crítica no podía ser otra cosa que interpretación: "Ciertamente -escribió en un pasaje decisivo para la finalidad del presente trabajo-, la crítica es una lectura profunda (o mejor dicho, perfilada); descubre en la obra cierto inteligible y en ello, es verdad, descifra y participa de 
una interpretación" (Barthes 1966, 74; cursiva última mía). Aunque parecía reconocerlo con desgana y como si hubieran sido sus detractores quienes le forzaran a ello, lo importante es que, tras algunos años de reservar el término solo para referirse al contrario, Barthes levantó la censura estructuralista no solo sobre el término interpretar, sino incluso sobre el de descifrar, dándoles de nuevo carta de naturaleza en el ámbito de los modernos estudios literarios.

Mucho tuvo que ver en este cambio el hecho de que, como revelaban otros pasajes del libro, se hubiera publicado ya ese primer gran fruto de la nueva hermenéutica francesa que fue De l'interprétation: essai sur Freud, de Paul Ricoeur (1965), del que Barthes había tomado prestada la tesis de la lengua literaria como lengua simbólica de sentido múltiple que estuvo en el origen de su propia y muy conocida teoría de la lengua literaria como "lengua plural" (Barthes 1966, 51-55). La deuda contraída con esta tesis de Ricoeur fue explícitamente reconocida por Barthes en nota a pie de página (52 n. 8). Sin embargo, y aunque ya no volvió a citarlo más a lo largo del libro, es muy posible que el Freud de Ricoeur le inspirara a Barthes algo más que su conocida teoría del plural del texto: otra de las novedades contenidas en Crítica y verdad consistió en empezar a utilizar el término "interpretación" para referirse no solo ya al tradicional empeño por dar con el significado único y definitivo del texto, sino también a un esfuerzo de distinto signo, mucho más respetuoso con la moderna tesis de la multiplicidad de sentidos del texto y, por lo mismo, menos orientado a la búsqueda de su presunta verdad. Que fue así como Barthes empezó a entender aquí la tarea interpretativa puede comprobarse atendiendo al pasaje en el que el autor matizó acto seguido su ya comentado reconocimiento de que la crítica descifraba y participaba de una interpretación:

Sin embargo, lo que devela no puede ser un significado (porque ese significado retrocede sin cesar hasta el vacío del sujeto), sino solamente cadenas de símbolos, homología de relaciones: el "sentido" que da de pleno derecho a la obra no es finalmente sino una nueva eflorescencia de los símbolos que constituyen la obra. Cuando un crítico extrae del pájaro y del abanico mallarmeanos un "sentido" común [...], no designa una última verdad de la imagen, sino únicamente una nueva imagen, ella misma suspendida. La crítica no es una traducción, sino una perífrasis. No puede pretender encontrar de nuevo el "fondo" de la obra... (74-75)

A tenor de lo aquí expuesto, Barthes había llegado a la conclusión de que la interpretación no tenía por qué seguir entendiéndose solo a la manera tradi- 
cional. De ahí, quizás, que no sintiera ya la necesidad de reprimir el término. Desde esta nueva perspectiva, más abiertamente hermenéutica, el teórico dejó ya de poner el énfasis en lo imprescindible del previo análisis inmanente (fórmula que de hecho desapareció por completo de Crítica y verdad), para hacer hincapié en el momento interpretativo de la crítica, es decir, el de exploración en los significados o "sentidos" de la obra (58). La crítica que Barthes definió y describió en este emblemático ensayo no llevaba ya el calificativo de estructural; era crítica a secas y se distinguía de su opuesto, la ciencia, solo y precisamente por su diferente acercamiento a la cuestión del sentido de la obra:

Podemos proponer -escribió al respecto- que se llame ciencia de la literatura (o de la escritura) al discurso general cuyo objeto es, no tal o cual sentido, sino la pluralidad misma de los sentidos de la obra, y crítica literaria a ese otro discurso que asume abiertamente, a su propio riesgo, la intención de dar un sentido particular a la obra. (58)

De acuerdo con esta definición de la crítica literaria, aquello que la caracterizaba frente a la ciencia, haciendo de ella una empresa arriesgada, era "la intención de dar un sentido particular a la obra". Conviene detenerse en esto. En otro momento del libro Barthes había afirmado que la pluralidad de sentidos de una obra no era algo que obedeciera solo a la variabilidad histórica de los lectores, sino también a la propia "disposición de la obra a la apertura" (52). Si la obra podía leerse de muchas maneras, había explicado, no era solo pues por "una inclinación de la sociedad al error", sino también y sobre todo porque estaba hecha de tal manera que, "por estructura", ella misma detentaba "muchos sentidos" (52). El pasaje de Crítica y verdad donde Barthes defendió esta importante teoría del plural del texto contenía, por supuesto, una referencia a la edición francesa del Obra abierta de Umberto Eco (52 n. 7). Sin embargo, tal como la defendió en ese concreto momento, su tesis del plural del texto se parecía más a la del otro autor citado, Paul Ricoeur, con quien Barthes compartía entonces la tesis de que la pluralidad de sentidos concernía a cualquier obra escrita en lengua simbólica y, por tanto, a las obras literarias de todos los tiempos, sin hacer distingos -como sí los había hecho en cambio Eco- entre un primer y un segundo grado de apertura, o entre obras clásicas y obras contemporáneas (Eco 112-13).

A pesar de entender que toda obra literaria, moderna o no, era constitutivamente plural, Barthes definió la crítica por "la intención de dar un sentido particular a la obra". Se ve, pues, que lo arriesgado de la empresa residía, pre- 
cisamente, en tener que dar un sentido particular a algo que, según se acababa de decir, se caracterizaba esencial y constitutivamente por poseer una pluralidad de sentidos. La incoherencia de esta primera teoría del plural fue acompañada, en Crítica y verdad, de un paradójico énfasis en la necesaria "coherencia" del discurso crítico, cuya validez se hizo residir precisamente en la "coherencia de los signos", es decir, en su capacidad para "desdoblar" los sentidos de la obra, haciendo "flotar un segundo lenguaje por encima del primer lenguaje de la obra" (Barthes 1966, 66; cursivas mías). De acuerdo con esto, la crítica tenía derecho a "transformar" (que no traducir) el texto, pero siempre y cuando lo hiciera con coherencia, es decir, transformándolo "todo" y "siempre en el mismo sentido" (66-67; cursiva mía). Todo esto implicaba, si bien se mira, que, aunque la crítica no podía dar con el sentido de la obra, su cometido era seguir actuando (escribiendo) como si realmente hubiera dado con él.

Debió de ser esta contradicción la que condujo a Barthes al experimento crítico-literario contenido en $S / Z$, donde el autor no solo se desdijo de su tesis sobre la posibilidad de una futura ciencia de la literatura, sino también de su primera teoría de la crítica-interpretación literaria. No parece casual que la rectificación en cuestión afectase especialmente a la regla de la coherencia del discurso crítico y, por tanto, a la supuesta necesidad de leer la obra en una sola y única dirección de sentido. La propuesta de $S / Z$ fue, como es sabido, justo la contraria: que la interpretación relevase a la ciencia y se hiciese cargo ella misma de la pluralidad de sentidos del texto, sin necesidad pues de centrarse en uno solo de esos sentidos. La consecuencia de este experimento debía ser la conversión de la crítica en un discurso tan plural y rico de sentidos como lo era el propio texto literario.

\section{LA INTERPRETACIÓN PLURAL}

El primer indicio de la transformación que supuso $S / Z$ estaría, precisamente, en el nuevo y mucho más frecuente uso que Barthes hizo aquí del término "interpretación". Lejos de reprimirlo como en "Las dos críticas", o de usarlo con reservas como en Crítica y verdad, el autor decidió usarlo nada más comenzar el libro, eligiéndolo como título de su segundo apartado y solo por detrás del dedicado a "La evaluación". La decisión de abrir $S / Z$ con estos dos apartados, "La evaluación” y "La interpretación”, sugiere además que, una vez superado el espejismo de la ciencia, el autor había decidido centrarse en el único discurso de cuya existencia había estado siempre convencido, es decir, el crítico- 
literario. Sin embargo, y confirmando el carácter más abiertamente hermenéutico de la nueva reflexión, Barthes abandonó la fórmula crítica literaria, sustituida aquí metonímicamente por sus dos operaciones, evaluación e interpretación. A diferencia de Crítica y verdad, el nuevo libro no versaba sobre la crítica literaria, sino sobre la interpretación, que Barthes, eso sí, presentó como inseparable de la evaluación.

El segundo indicio de que $S / Z$ se inscribía ya en una problemática abiertamente hermenéutica se encuentra precisamente en la irrupción del término "hermenéutico" en el discurso teórico de Barthes. No "hermenéutica" en alusión a una disciplina en la que optó por no reconocerse, pero sí "hermenéutico", adjetivo que empleó para identificar uno de los cinco códigos de lectura del relato balzaciano, el "código hermenéutico" (Barthes 1970, 12), así como para caracterizar la clase de relato resultante de la presencia de este código, a saber, el "relato hermenéutico" (63). Todo esto, junto con la nueva prodigalidad a la hora de utilizar el término "sentidos", mucho más frecuente aquí que en sus trabajos anteriores, invita a considerar este libro como inscrito en la problemática hermenéutica, más allá de que su autor optara por entender "lo hermenéutico" de una manera no del todo positiva, y más allá también de que las tesis en él expuestas coincidiesen o no con las que en ese momento estaban defendiendo los autores más representativos de este paradigma teórico.

El principal objetivo de Barthes en $S / Z$ fue, como ya he avanzado, rectificar la tesis que él mismo había defendido en Crítica y verdad en relación con la crítica (interpretación) literaria: "Interpretar un texto -escribió por eso enseguida - no es darle un sentido (más o menos fundado, más o menos libre), sino por el contrario apreciar el plural de que está hecho" (3; cursiva mía). Los que conocieran bien la obra de Barthes debieron de advertir que el contenido polémico del aserto iba dirigido en realidad contra sí mismo, o mejor, contra su anterior convicción de que la intención de la crítica era siempre "dar un sentido particular a la obra" (1966, 58; cursiva mía). También tuvieron que percibir que Barthes estaba proponiendo ahora justo lo contrario que en Crítica y verdad, a saber, que la interpretación se diese por cometido deshacer cualquier ilusión de coherencia, no ya solo en la obra literaria, sino también -en correspondencia especular con ella- en el propio discurso crítico. Y esto no para alcanzar ninguna clase de validez, otro de los términos que desaparecieron del nuevo discurso barthesiano, sino con el único fin de "afirmar, frente a toda indiferencia, el ser de la pluralidad" (1970, 3). 
Lejos, pues, de estar obligada a construir un "todo" homogéneo y coherente a partir de uno de los (presuntos) sentidos de la obra literaria, la nueva interpretación tenía que "dispersar" o "diseminar" todos los (presuntos) sentidos que fuera capaz de detectar o movilizar en la obra, sin renunciar a ninguno de ellos. El defecto de la crítica no era ya la incoherencia, sino, al contrario, esa excesiva coherencia que, a juicio del nuevo Barthes, solo podía ser el resultado de ignorar u obviar la complejidad estructural inherente a la mayoría de los textos literarios, incluidos buena parte de los "legibles" o "clásicos". De ahí que la nueva recomendación en el trato crítico-literario con el texto fuera la de "evitar estructurarlo demasiado, evitar darle ese suplemento de estructura que le vendría de una disertación y lo clausuraría” (9). Puesto que la propia obra no era un "todo" perfectamente estructurado, homogéneo y coherente, ${ }^{5}$ el trabajo de la interpretación tenía que evidenciar este hecho mediante el procedimiento de volverse él mismo tan heterogéneo, inconsistente y desestructurado como le reclamase cada obra concreta $-\mathrm{y}$ teniendo en cuenta que, como veremos luego, el grado de pluralidad e inconsistencia no era idéntico en todas las obras literarias (3)-. Tal como el propio Barthes la puso en práctica en relación con Sarrasine, la interpretación dejaba de ser el discurso que disimulaba o enmascaraba la esencial falta de unidad del texto para convertirse en la "práctica" ella misma "textual" que la ponía de manifiesto en su propia complejidad estructural, conseguida a base de incorporar la "digresión (forma mal integrada por el discurso del saber) en la escritura misma del comentario" (9).

Conviene aclarar que, al sostener la ausencia de un todo o una estructura en el texto literario, Barthes estaba empleando estos conceptos tal y como por entonces solía hacerse, es decir, en singular. Su intención no era, por tanto, renunciar a ellos, sino empezar a usarlos de una forma por entonces novedosa, es decir, en plural. Si no había "un todo del texto", era porque había varios. La obra no estaba constituida por un sistema, sino por varios -o incluso "múltiples"- sistemas de sentido (3). De ahí que el autor concibiera $S / Z$ también como una contribución a la semiología y que no viera ninguna necesidad de renunciar al concepto de "análisis estructural" (8). Desde la perspectiva de Barthes, quien no tuvo conciencia de estar inaugurando el posestructuralismo, $S / Z$ seguía siendo un trabajo de análisis estructural, si bien realizado no ya desde las

5. "Si el texto está sometido a una forma -dijo a este respecto en $S / Z$ - esta forma no es unitaria, estructurada, acabada" (15). 
premisas y conceptos del primer estructuralismo saussureano-jakobsoniano, sino a partir de un estructuralismo rectificado. Se trataba, por supuesto, de la nueva especie de semiología no cientificista que había penetrado en Francia de la mano de Kristeva y de su propuesta de "dinamización del estructuralismo" inspirada en Bajtin (Kristeva 2). Tal como Barthes empezó a verlo a la luz de esa nueva semiología, y en coincidencia con las tesis prácticamente coetáneas de Lotman (1970), la pluralidad de sentidos del texto no podía sino ser el efecto semántico de la asimismo plural "estructuración" (que no estructura) de la obra (Barthes 1970, 15). Por lo mismo, una interpretación que quisiera dar cuenta de esa estructuración estaba obligada a dispersarse (dividirse) ella misma en varios análisis-interpretaciones de cada una de sus superpuestas estructuras (8-9).

Así entendida, la interpretación dejaba de consistir en hacer hablar a la obra desde un solo lenguaje, elegido arbitrariamente por el crítico entre todos los que el texto podía sugerirle, para pasar a ser una "lectura... plural" (11) realizada sin pasar por alto ni uno solo de todos los lenguajes o "códigos" que cada texto pusiera en juego (14). Los famosos cinco "códigos" en los que Barthes dividió su análisis-interpretación de Sarrasine eran, pues, los cinco lenguajes o sistemas (cada uno dotado de significantes y significados) que su subjetividad crítica ${ }^{6}$ había sido capaz de percibir en el relato de Balzac. El objetivo no era, sin embargo, "desvelar" o "descubrir" el "texto verdadero" (12), lo que habría sido equivalente otra vez a afirmar la posibilidad de una interpretación objetiva. Para evitar toda recaída en este espejismo, fue seguramente para lo que insistió en el carácter de "trabajo" y "juego", no solo del texto, sino también de la interpretación. ' Que estos dos términos, juego y trabajo, fuesen aquí prácticamente sinónimos debería disipar el malentendido según el cual $S / Z$ contendría una invitación a una actitud irresponsable y poco seria en relación con la interpretación. Basta por otra parte adentrarse en la detenida, morosa, difícil y rigurosa lectura que el teórico realizó aquí del relato balzaciano para entender que, más allá del grado de acuerdo que se pueda tener con sus propuestas, no eran fruto de ningún hedonismo irresponsable. Su concepto de

6. Al igual que en Crítica y verdad, la interpretación se seguía reconociendo aquí como un trabajo realizado desde la "subjetividad" del crítico. Lo que Barthes entendía por subjetividad no era, sin embargo, lo que hasta entonces se entendía habitualmente: no se trataba de una "identidad" esencial e invariable del sujeto lector, sino de una subjetividad no idéntica a sí misma, plural, atravesada por varios lenguajes (o voces en sentido bajtiniano) y siempre en movimiento (7).

7. Sobre el concepto de "trabajo del texto" en $S / Z$, ver Cuesta Abad. 
juego, muy deudor de la teoría wittgensteiniana de los juegos de lenguaje, apuntaba una vez más, y en la línea ya inaugurada en Crítica y verdad, a la imposibilidad de cerrar o detener el significado de la obra, incluso cuando, como en $S / Z$, se abordaban ya en plural, es decir, como significados o sentidos múltiples.

Ciertamente, habría que convenir en que, si la certidumbre de la objetividad no se entendía posible ni siquiera cuando al texto se le atribuía una sola estructura, menos podría serlo a partir del momento en que se lo describió como texto superestructurado. De ahí que el autor optara en este libro por referirse al trabajo interpretativo de "encontrar sentidos" en los atinados términos de "aproximación incansable":

Leer es encontrar sentidos, y encontrar sentidos es designarlos, pero esos sentidos designados son llevados hacia otros nombres; los nombres se llaman, se reúnen y su agrupación exige ser designada de nuevo: designo, nombro, renombro: así pasa el texto: es una nominación en devenir, una aproximación incansable, un trabajo metonímico [...]; la lectura no consiste en detener la cadena de los sistemas, en fundar una verdad, una legalidad del texto y, en consecuencia, provocar las "faltas" de su lector; consiste en embragar esos sistemas no según su cantidad finita, sino según su pluralidad. (7; cursiva mía)

\section{INTERPRETACIÓN/HERMENÉUTICA}

Como se avanzaba ya al comienzo del presente trabajo, muchos estudiosos de Barthes estarían en profundo desacuerdo con la idea, que aquí acaba de exponerse, de que $S / Z$ sea un libro de o sobre interpretación literaria. Recordemos que, para Jonathan Culler, la intención de Barthes en este libro no había sido "interpretar Sarrasine, sino analizarlo como una construcción intertextual" (Culler 1987, 97-98). Sin embargo, según se ha visto aquí, Barthes no entendió nunca, ni siquiera en el periodo estructuralista, que analizar e interpretar fuesen tareas incompatibles. Tampoco lo hizo en $S / Z$, donde lo ocurrido fue, más bien, que dejó de concebirlas como dos fases diferentes de la tarea crítica para empezar a entenderlas y practicarlas como hemos visto que lo hacía Ricoeur, es decir, de una manera más dialéctica, circular y, por tanto, también más propiamente hermenéutica. En la teoría formulada en $S / Z$, "análisis estructural” y "lectura plural" serían, por consiguiente, expresiones sinónimas e intercambiables. 
Para poder afirmar que Barthes no se propuso interpretar, sino solo analizar, Culler tuvo que pasar por alto la explícita declaración de intenciones (interpretativas) realizada en el apartado "La interpretación", así como en otros muchos momentos del libro. Y si lo hizo así, debió de ser porque su lectura de S/Z en 1983 estaba todavía muy condicionada por la misma resistencia a la interpretación que Barthes, en cambio, ya había dejado atrás. Confirma esta hipótesis el hecho contrastable de que todavía a día de hoy Culler sea uno de los pocos teóricos literarios que sigue abogando por una estricta diferencia entre poética y hermenéutica, además de alertar a sus colegas contra "la tentation de l'hermenéutique" (Culler 2012, 6).

No se trata, sin embargo, de negar la parte de responsabilidad que el propio Barthes habría tenido en esta lectura antihermenéutica de su libro. Ciertamente, el teórico abandonó aquí toda reserva hacia la interpretación, pero también operó un desplazamiento semántico por el que toda la carga negativa que antes había proyectado sobre el término interpretación se traspasó al nuevo término hermenéutico. Como ya se ha avanzado, Barthes usó aquí este término en forma adjetiva y únicamente para caracterizar uno de los cinco códigos movilizados por el relato Sarrasine, el llamado "código hermenéutico" (12), de cuya presencia en el texto balzaciano se derivaba a su vez la posibilidad de caracterizarlo como "relato hermenéutico" (63). Por otra parte, el "código hermenéutico" fue definido como aquel cuya función era la de "articular, de diversas maneras, una pregunta, su respuesta y los variados accidentes que pueden preparar la pregunta o retrasar la respuesta, o también formular un enigma y llevar a su desciframiento" (12; cursiva mía). Según esto, Sarrasine era un relato hermenéutico justamente porque, como la hermenéutica misma, prometía el desciframiento de una verdad final. Como, además, un relato así era un texto "fechado, ligado a la civilización kerigmática del sentido y de la verdad, de la llamada y la plenitud" (63), lo hermenéutico quedó asociado aquí a una cierta manera clásica e "inactual" de "contar" y, por tanto, también de interpretar: la que consistía en esperar (o buscar) la "verdad" que llegaría al final del relato (o del análisis).

Así entendido, lo hermenéutico venía a coincidir con lo que $S / Z$ llamaba también "lo legible", es decir, con la clase de textos "entregados a la ley del Sig-

8. No era, con todo, en esto donde a juicio de Barthes se concentraba "la falta de actualidad balzaciana”. El teórico explicó que la esencia de lo que en Balzac no podía ser (re)-escrito eran los "códigos culturales", fuente de los "estereotipos" que plagaban el texto en forma de "sabiduría" o "ciencia" (172-73). Cabe pensar, pues, que lo hermenéutico (el relato-enigma) no le parecía, en realidad, tan inactual. 
nificado", inscritos en "el sistema de clausura occidental" y fabricados a partir de "un régimen particular de sentido" (5). Y, por tanto, coincidía también con lo que el primer apartado del libro presentaba como el "contravalor", el "valor negativo, reactivo" frente al cual se establecía el valor positivo de "lo escribible" (2). Parece, pues, comprensible que a pesar de ser el único libro de Barthes que versa por entero sobre la interpretación literaria, $S / Z$ pueda ser tenido por un libro antihermenéutico. Si se atiende a lo formulado en ese primer apartado del libro, lo hermenéutico-legible era algo negativo y reaccionario contra lo que se erigía precisamente el valor positivo de lo escribibleindecidible. Y S/Z sería, entonces, un libro de oposición a la tesis central de la hermenéutica, la de la necesidad-posibilidad de interpretar textos literarios; tesis a la que el denominado posestructuralismo habría opuesto, apoyándose precisamente en Barthes, una teoría absolutamente contraria, la del texto como "galaxia de significantes" de significación indecidible. De ahí, precisamente, las reservas hacia $S / Z$ de Merquior, para quien la interpretación se habría convertido, en este libro, en "una interminable serie de glissandi caprichosos" (Merquior 200).

Ocurre, sin embargo, que la negatividad de lo legible y, por tanto, de lo hermenéutico, no es a lo largo de $S / Z$ tan clara y unívoca como Barthes dio a entender en el primer apartado del libro. De hecho, nada más comenzar el segundo, el dedicado justamente a la interpretación, el autor matizó la tajante valoración que acababa de hacer introduciendo una primera y gran duda sobre los textos positivos, los escribibles: "Tal vez -escribió- no haya nada que decir de los textos escribibles" (2; cursiva mía). El primer y principal motivo de que no hubiese nada que decir sobre ellos era, siguió explicando, que no se sabía "dónde encontrarlos" (2). Habría, pues, que inferir que, al igual que la ciencia de la literatura en Crítica y verdad, el texto escribible no era algo que existiera todavía: "El texto escribible -dijo Barthes, en efecto- no es una cosa, es difícil encontrarlo en librerías" (2). Solo existía -concluyó- en "nosotros en el momento de escribir" (2). De ahí que Eric Marty haya podido referirse a este texto escribible en términos de "non-lieu" e incluso de "utopie" (Marty 90-91).?

Pero había todavía un segundo motivo por el que Barthes pensó que tal vez no se podía decir nada de los textos escribibles. Por su propia definición de texto "absolutamente plural" (3), el texto escribible, caso de existir algún día, supondría precisamente la desaparición del discurso propiamente llamado

9. Sobre el contenido político de esta utopía del texto puede verse también Kaufmann. 
crítica literaria, que sería sustituido por un discurso completamente creativo, la re-escritura: "Siendo su modelo productivo (y no ya representativo), suprime toda crítica que, al ser producida, se confundiría con él: reescribirlo no sería sino diseminarlo, dispersarlo en el campo de la diferencia infinita" (2; cursiva mía).

Conviene ahora reparar en que era a este texto absolutamente plural, al que Barthes se refirió también como "texto ideal" (e inexistente), al único que convenía la famosa descripción del texto como "galaxia de significantes" a la que se podía acceder "a través de múltiples entradas" y cuyos "códigos" eran tan numerosos (infinitos) que "su número no se cierra nunca" (3). Quiero decir con esto que lo que se tiene por la teoría posestructuralista del texto no sería, en realidad, una teoría propiamente dicha, sino más bien un desiderátum, un proyecto, una idea reguladora o, incluso, una "théorie-fiction" (Bremond/ Pavel 54). Lo que esta teoría describía no era, ni mucho menos, todos los textos de la cultura; pero tampoco unos pocos, puesto que no describían nada que realmente existiera. De ahí que Andrea del Lungo $(2016,146)$ se haya referido recientemente a esta teoría barthesiana como una descripción "fantasmática". Por lo mismo, hay que entender que fue solo a estos textos ideales pero inexistentes a los que asimismo atribuyó las cualidades de "multivalentes, reversibles y francamente indecidibles" (4; cursiva mía). Frente a ellos, Barthes situó explícitamente lo real-empírico, es decir, "la enorme masa de nuestra literatura", compuesta por "textos legibles" (3). Lo habitual es creer que estos textos legibles habrían sido reprobados o incluso "condenados" por el teórico (ver Bremond/Pavel 55), pero en realidad su falta de idealidad quedaba compensada, otra vez, por la prioridad ontológica de su real y efectiva existencia. De ahí la paradoja de que fuese a uno de estos supuestamente reprobables textos legibles, Sarrasine, al que el autor dedicó el trabajo de lectura-interpretación llevado a cabo en $S / Z$.

De la argumentación barthesiana se infiere, por otro lado, que el teórico excluyó también la existencia de textos absolutamente legibles (ver del Lungo 2002 , 6). Su propuesta no consistía, pues, en una rígida oposición binaria entre lo legible y lo escribible, sino en entender estas dos categorías como los potenciales puntos extremos de una escala que necesariamente debía incluir también varias (o incluso múltiples) categorías intermedias. Sarrasine, la narración elegida por Barthes para ilustrar su nueva teoría del texto y de la interpretación, no era entonces un texto ideal-escribible, pero tampoco un texto completamente legible-clásico: "Estamos -explicó él mismo- frente a textos no to- 
talmente plurales: textos cuyo plural es más o menos parsimonioso" (3). Se trataba de textos que, aunque entregados a la ley del Significado y obedientes a las leyes clásicas de la representación, no carecían por completo de las cualidades asignadas a lo ideal-escribible, ni, por tanto, de cierta dosis de indecidibilidad (64). Barthes habló en concreto de un "plural limitado" que aseguraba "una diseminación (limitada) de los sentidos" y cuyo fundamento era la "connotación", entendida aquí como el "modesto instrumento" de esa limitada pluralidad de sentidos de un texto clásico o legible (5).

Puesto que el texto analizado pertenecía a esta categoría intermedia, se entiende que el discurso crítico-interpretativo ensayado aquí por Barthes no fuera exactamente el que se tiene por rigurosamente posestructuralista: el de la ilimitada diseminación del significante. Se trataría, más bien, de una suerte de híbrido, a medio camino entre el comentario-interpretación tradicional (lo hermenéutico) y la reescritura (lo anti-hermenéutico). Y fue a este discurso mixto, que necesariamente tenía todavía algo de hermenéutico, al que optó por dar el nombre de "interpretación (en el sentido que Nietzsche le daba a esta palabra)" (3). En el caso concreto de Sarrasine, las partes más hermenéuticointerpretables del relato se correspondían lógicamente con las significaciones derivadas del "código hermenéutico", pero también con las del "código proairético" (el de las acciones y los comportamientos). Las partes más reescribibles eran, en cambio, las relacionadas con los otros tres códigos, los más "reversibles" o escribibles del relato balzaciano: el sémico, el simbólico y los culturales. La conjunción de todos estos códigos era, en fin, la que garantizaba la posibilidad crítica de una limitada diseminación de los sentidos.

Lo más interesante de este proceder barthesiano sería, a mi juicio, que ponía en escena la importancia de tener en cuenta cómo se había fabricado el texto, desde qué lógica o "régimen de sentido" se había escrito (5). En el caso de los textos legibles, o moderadamente plurales, esa lógica era "la ley del Significado", y de ahí que el trabajo de la interpretación no pudiera consistir exactamente en lo mismo que habría consistido de tratarse de un texto más moderno y menos moderadamente plural. Por consiguiente, lo que Barthes puso en práctica en $S / Z$ no fue "la" interpretación o lectura plural, sino una concreta modalidad de lectura plural, la que convenía a la clase de textos moderadamente plurales a la que pertenecía Sarrasine; o incluso, para ser más precisos, la concreta modalidad de lectura plural que convenía a ese y solo a ese texto (Sarrasine), del que no en balde había afirmado, nada más arrancar el libro, su "diferencia" (1). 
La relevancia de lo propuesto en este libro no residiría solo, entonces, en esa teoría de la interpretación plural con la que rectificó la más monológica teoría de la crítica contenida en Crítica y verdad. Igualmente decisiva sería también la transformación que experimentó aquí la propia teoría del plural del texto. Frente a lo afirmado en Crítica y verdad, donde la pluralidad se había definido como una cualidad inherente por igual a todos los frutos de la lengua simbólica -en teoría que Barthes tomó directamente del primer Paul Ricoeur-, S/Z planteaba una tesis más cercana ya a la de Umberto Eco, diferenciando entre grados de apertura en los diferentes textos. Solo que, mientras que el semiótico italiano había distinguido únicamente dos grados de apertura y, por tanto, dos grandes clases de textos; la propuesta de Barthes consistió en fundar una nueva "tipología de los textos" (4-5) que los clasificara y ordenara de manera asimismo muy plural, dependiendo precisamente de su variable "cantidad" o grado de apertura. De resultas de esta mucho más precisa operación clasificatoria, los textos podrían repartirse en tipos en función de "una cierta cantidad, del más o menos que puede movilizar cada texto" (3). Barthes no concretó, sin embargo, cuántos ni cuáles podían ser esos diferentes tipos de textos, limitándose por el momento a identificar solo el tipo concreto al que pertenecía el relato balzaciano, el de los textos que, de manera todavía bastante imprecisa, caracterizó como "moderadamente plurales".

Por incompleta que estuviera la tipología, se trataría de algo muy relevante desde el punto de vista hermenéutico. Y esto porque, al hacerse ella misma más plural, la nueva teoría del texto dejó abierta la vía a una nueva y también más coherente pluralidad metodológica. Puesto que Barthes contempló la posibilidad de que existieran muchos tipos de textos diferentes en función de su mayor o menor grado de apertura, excluyó de entrada que su concreto comentario de Sarrasine pudiera convertirse en el "modelo" de todos los comentarios (ver Sirvent 243). A diferencia de lo que pasaba en sus trabajos anteriores, donde la descripción ideal de la tarea crítica se apoyaba en lo previamente realizado en sus propios trabajos críticos (en especial, en "L'homme racinien"), lo ejecutado en $S / Z$ en relación con el relato balzaciano no se proponía como una técnica o procedimiento susceptibles de universalización. Se trataba solo -y nada menos- que del "trabajo" realizado sobre un concreto relato y a partir de su "diferencia". Y, por consiguiente, era pensando y abordando la diferencia de cada texto como cada analistaintérprete tendría que llevar a cabo su propio y personal trabajo de interpretación, no solo ya sin objetividad, sino también -y tal como Gadamer 
acababa de proponer- sin "método". La conclusión de todo esto es que, más allá de las connotaciones negativas que Barthes optó aquí por darle a "lo hermenéutico", existen muchas razones para entender este libro como la más completa y decisiva contribución del autor a la teoría de la interpretación literaria.

\section{OBRAS CITADAS}

Albaladejo, Tomás. "La crítica como metatexto: Roland Barthes". Anthropos. Cien años de Roland Barthes. Coords. Carlota Fernández-Jáuregui y Tomás Albaladejo. 242 (2015): 109-18.

Baena, Enrique. "Roland Barthes y la literatura: indagaciones sobre un repertorio conceptual". Anthropos. Cien años de Roland Barthes. Coords. Carlota Fernández-Jáuregui y Tomás Albaladejo. 242 (2015): 9-17.

Barthes, Roland. "Histoire ou littérature?". 1960a. Sur Racine. Paris: Seuil, 1963. 137-57.

Barthes, Roland. "L'homme racinien". 1960b. Sur Racine. Paris: Seuil, 1963. 9-126.

Barthes, Roland. Sur Racine. Paris: Seuil, 1963a.

Barthes, Roland. "Las dos críticas". 1963b. Ensayos criticos. 1964. Ensayos criticos seguidos de La escritura misma: sobre Roland Barthes, por Susan Sontag. Trad. Carlos Pujol. Barcelona: Seix Barral, 1983. 293-99.

Barthes, Roland. Ensayos críticos. 1964. Ensayos críticos seguidos de La escritura misma: sobre Roland Barthes, por Susan Sontag. Trad. Carlos Pujol. Barcelona: Seix Barral, 1983.

Barthes, Roland. Crítica y verdad. 1966. Trad. José Bianco. México: Siglo XXI, 1981.

Barthes, Roland. S/Z. 1970. Trad. Nicolás Rosa. México: Siglo XXI, 1987.

Bremond, Claude, y Thomas Pavel. De Barthes à Balzac: Fictions d'un critique, critiques d'une fiction. Paris: Albin Michel, 1998.

Chico Rico, Francisco. "La retórica en el pensamiento de Roland Barthes: historia y sistema". Anthropos. Cien años de Roland Barthes. Coords. Carlota Fernández-Jáuregui y Tomás Albaladejo. 242 (2015): 31-42.

Cuesta Abad, José Manuel. "Roland Barthes y el trabajo del texto". Anthropos. Cien años de Roland Barthes. Coords. Carlota Fernández-Jáuregui y Tomás Albaladejo. 242 (2015): 19-30.

Culler, Jonathan. Barthes. 1983. Trad. Pablo Rosenblueth. México: FCE, 1987. 
Culler, Jonathan. "Pour la Poétique". Fabula-LbT 10 (2012). 3 de marzo de 2018. http://www.fabula.org/lht/10/culler.html.

Eco, Umberto. Obra abierta. 1962. Trad. Roser Berdagué. Barcelona: PlanetaDe Agostini, 1979.

Gadamer, Hans-Georg. Verdad y método. 1960. Trads. Ana Agud de Aparicio y Rafael de Agapito. Salamanca: Sígueme, 1997.

Jakobson, Roman. "Lingüística y poética". 1958. Ensayos de lingüística general.

Trads. Josep M. Pujol y Jem Cabanes. Barcelona: Planeta-De Agostini, 1985. 347-94.

Kaufmann, Vincent. La Faute à Mallarmé: L'Aventure de la théorie littéraire. Paris: Seuil, 2011.

Kristeva, Julia. "Bajtin, la palabra, el diálogo y la novela". 1967. Intertextualité: Francia en el origen de un término y el desarrollo de un concepto. Selec. y Trad. Desiderio Navarro. La Habana: UNEAC/Casa de las Américas/ Embajada de Francia en Cuba, 1997. 1-24.

Lotman, Yuri M. Estructura del texto artístico. 1970. Trad. Victoriano Imbert. Madrid: Istmo, 1982.

Lungo, Andrea del. " $S / Z$, ou les envers de la critique balzacienne". Barthes, au lieu du roman. Eds. Alexandre Gefen y Marielle Macé. Paris: Desjonquères/Nota Bene, 2002. 111-25. 3 de marzo de 2018. <http://www.andreadellungo.com/wp-content/uploads/2013/06/SZ.pdf >.

Lungo, Andrea del. "Éloge du lisible (Sur S/Z)". Carnets: revue électronique d'études françaises 6 (2016): 143-52.

Mannheim, Karl. Ideología y utopía. 1936. Trad. Salvador Echevarría. México: FCE, 1987.

Marty, Eric. "Roland Barthes et le discours clinique: lecture de S/Z". Essaim: Revue de Psychanalyse 15.2 (2005): 83-100.

Merquior, José-Guilherme. De Praga a París: critica del pensamiento estructuralista y posestructuralista. 1986. Trad. Stella Mastrangelo. México: FCE, 1989.

Ricoeur, Paul. Freud: una interpretación de la cultura. 1965. Trad. Armando Suárez. México: Siglo XXI, 1970.

Ricoeur, Paul. Teoría de la interpretación. Discurso y excedente de sentido. 1976. Trad. Graciela Monges Nicolau. México: FCE, 1995.

Ricoeur, Paul. Ideología y utopía. 1986. Trad. Alberto L. Bixio. México: Gedisa, 1991.

Sirvent Ramos, Ángeles. Roland Barthes: de las críticas de interpretación al análisis textual. Alicante: Universidad de Alicante, 1989. 
Sontag, Susan. "Contra la interpretación”. 1964. Contra la interpretación y otros ensayos. Trad. Horacio Vázquez Rial. Barcelona: Seix-Barral, 1967.

Szondi, Peter. Introducción a la hermenéutica literaria. 1975. Trad. Joaquín Chamorro Mielke. Introd. J. M. Cuesta Abad. Madrid: Abada, 2006.

Wahnón, Sultana. "Sur Racine: la hermenéutica estructural de Roland Barthes". Teoría de la literatura y de la interpretación literaria. Vigo: Academia del Hispanismo, 2008. 111-24.

Wahnón, Sultana. "La hermenéutica constructiva: una propuesta renovadora de teoría literaria". Teoría de la literatura (Restos). Ed. Javier Morales Mena. Lima: Facultad de Letras y Ciencias Humanas de la Universidad Nacional Mayor de San Marcos/Editorial San Marcos, 2012. 91-119. 